\title{
The IDEA Model as an Effective Instructional Crisis and Risk Communication Framework to Analyze the CDC's Messages Aimed at Hispanics in the COVID-19 Era
}

\author{
Sofia E. Salazar \\ Ph.D. Student at the University of Central Florida \\ 12405 Aquarius Agora Drive, Florida, Orlando United States
}

\begin{abstract}
This study explores, through a thematic analysis, the messages published in Spanish in the Holiday Celebrations and Small Gatherings [Celebraciones y pequeñas reuniones por las fiestas] section of the Center for Disease Control and Prevention's website (CDC). To analyze these messages, this study used the IDEA model. The conclusions suggest CDC prioritized internalization and action messages over distribution and explanation in this section of the website. The conclusions also show that although the CDC incorporated all elements of the IDEA model in the messages, the information shared was a mere translation of the English version of the Holiday Celebrations and Small Gatherings section of the website, showing thus, that the messages did not seem to be created to appeal to Hispanics intentionally. Suggestions are offered to improve the communications delivered by the CDC to the Hispanic community in the United States.
\end{abstract}

Keywords - CDC, communication, coronavirus, Hispanics, IDEA model

SUGGESTED CITATION: Salazar, E. S. (2021). The IDEA Model as an effective instructional crisis and risk communication framework to analyze the CDC's messages aimed at hispanics in the COVID-19 era. Proceedings of the International Crisis and Risk Communication Conference, Volume 4 (pp. 45-48). Orlando Fl: Nicholson School of Communication and Media. https://doi.org/10.30658/icrcc.2021.11

\section{INTRODUCTION}

The coronavirus disease 2019 (COVID-19) has altered everybody's life since the moment it became a pandemic. In the United States, many people have died, and many others still struggle to either stay safe from getting the virus or recover after contracting the virus. Therefore, in an attempt to reduce the consequences of the virus, the Center for Disease Control and Prevention (CDC), the leader in the country in researching and developing responses to diseases, has been creating guidelines for people to stay safe from getting or spreading the coronavirus. Despite the efforts being conducted by this organization to mitigate the virus effects, contagions are still rising. In fact, as the holidays approach, experts such as Dr. Anthony Fauci and the director of the National Institute of Allergy and Infectious Diseases, expect that infections will increase even more during the holidays [7]. In light of this problem, Hispanics are of particular concern because, since the pandemic started, they have been impacted disproportionally by the virus in the United States [2]. Communication scholars agree that the spread levels of coronavirus are linked to a lack of effective instructional crisis and risk messages about the virus, its consequences, and protective actions, among other information [9]. When communicating to culturally diverse audiences about crisis and risk, experts such as Petrun et al. [6] emphasize the importance of tailoring messages to the cultural expectation of diverse populations to motivate self-efficacy and protective action. Thus, to contribute to the research revolving around COVID-19 and the construction of messages distributed by health officials in the US to instruct Hispanics about the virus, this study explores, through a thematic analysis, the messages published in Spanish in the Holiday Celebrations and Small Gatherings [Celebraciones y pequeñas reuniones por las fiestas] section of the CDC's website [3]. To analyze these messages, this research will use the IDEA model [8] as a theoretical framework.

\section{LITERAURE REVIEW}

Hispanics are leading in COVID-19 cases in the United States [2]. In October 2020, the CDC [2] reported that about 
$32.4 \%$ of deaths caused by COVID-19 were Latinx individuals. Overall, data shows that Hispanics are more likely to die from COVID-19 than other races such as Black, White, Asians, and American Indian/Alaska Native [2]. This situation also demonstrates that despite the CDC's efforts to instruct individuals on the guidelines to stay safe, Hispanics keep struggling to implement these guidelines [1]. As a matter of fact, Hispanics living in the United States are still attending and organizing large family and social gatherings despite the restrictions [1]. Experts expect these social and family gatherings to increase during the holiday season [7]. Therefore, to prevent this situation from worsening, the CDC even developed messages that explain how to safely approach the holidays. These messages can be evidenced in the "Holiday Celebrations and Small Gatherings" [Celebraciones y pequeñas reuniones por las fiestas] section on the CDC website. In this section, the CDC addresses in Spanish considerations for small gatherings with family and friends, recommendations for hosting or attending a gathering, and considerations on food and drinks treatment at small holiday gatherings. Other suggestions provided include instructions for traveling or overnight stays and steps to take if COVID-19 is contracted at a small gathering [3]. Translating these messages seems particularly important because $32 \%$ of Hispanics living in the United States claim not to be fluent in English [5]. About translations, researchers in the crisis and risk communication field have demonstrated that although translating messages is a good strategy, it is not enough to motivate protective actions and self-efficacy among diverse audiences [6]. Sellnow and Sellnow [8] agree with this when stating that crisis and risk messages should also be developed to attain affective, cognitive, and behavioral outcomes because they enhance individuals' capability to take the appropriate protective actions when in trouble or at risk. Therefore, to analyze if the COVID-19 messages crafted and distributed to the Hispanic community through the "Holiday Celebrations and Small Gatherings" section of the CDC's website are including affective, cognitive, and behavioral elements, this study will use the IDEA model as its theoretical framework.

\section{THE IDEA MODEL}

This model focuses on appealing to cognitive, behavioral, and affective learning outcomes. Scholars in instructional crisis and risk communication consider that creating messages to produce cognitive outcomes prompt audiences to understand what is happening, why the disaster happens, or how it happens [8]. They also agree that creating messages that seek to attain affective outcomes can develop a sense of the crisis's relevance among the population. Lastly, researchers also believe that messages that seek behavioral learning outcomes aim to instruct the individual to take effective protective actions [8]. The model involves 4 components: Internalization, distribution, explanation, and action [8]. In the internalization step, communicators should identify the audiences who need to be warned about the crisis or risk and inform them how they can be impacted. Sellnow and Sellnow [8] insist that spokespersons should respond to questions such as "How am I or my loved ones affected?" (p .68). In the distribution step, communicators seek to identify the appropriate channels to reach the audience at risk or in crisis. The explanation component addresses the value of explaining information in ways that can be understood by a non-scientific audience. Sellnow and Sellnow [8] agree that a question that should be responded to in this step is "What is happening and why?" (p. 73). Lastly, the action component seeks to focus on what to do to stay safe. Sellnow and Sellnow [8] consider that this element involves the key elements to get receivers to take appropriate action. Sellnow and Sellnow [8] suggest that the question responded in this component of the model is "What to do?" Or "What not to do?" (p.74). Thus, this study will use the IDEA model to analyze the messages developed by the CDC in Spanish in the "Holiday Celebrations and Small Gatherings" section of its website by responding to the following research question: To what extent the COVID-19 do messages crafted in Spanish in the CDC "Holiday Celebrations and Small Gatherings" [Celebraciones y pequeñas reuniones por las fiestas] section of its website employ the four elements of the IDEA model for effective instructional risk and crisis communication?

\section{METHODS OR PROCEDURES}

The author of this study conducted a thematic analysis of the Spanish version of the "Holiday Celebrations and Small Gatherings" section of the CDC website updated on November 27th, 2020. A thematic analysis was selected as the method of this study because it is the best way to explore the extent to which the content of the messages themes that fall under the four components of the IDEA model are employed.

The author focused on collecting the messages published in the Spanish version of the website because Spanish is still used among many Hispanics living in the United States. In fact, Krogstad et al. [5] states that when it comes to speaking English, around 16,000,000 Hispanics living in the United States "rate their speaking ability as less than very well" or do not speak the English language at all (para. 8). Also, the author focused on the CDC website because around $74 \%$ of Hispanics living in the US prefer getting their news from the internet.

This study used an etic approach to analyze the content in the Spanish version of the "Holiday Celebrations and Small Gatherings" [Celebraciones y pequeñas reuniones por las fiestas] section of the CDC's website (2020g). In the case of this research, to guide the thematic analysis, the author used the IDEA model and its four components: internalization, distribution, explanation, and action [8]. In other words, the "Holiday Celebrations and Small Gatherings" [Celebraciones y pequeñas reuniones por las fiestas] section was coded based on the IDEA model. 


\section{RESULTS}

To evaluate the IDEA model's application, 138 messages were thematically coded for internalization, distribution, explanation, and action in the Spanish version of the "Holiday Celebrations and Small Gatherings" section of the CDC website. Of the 138 messages coded, $27(19.57 \%)$ were internalization, of the 138 messages coded, $9(6.52 \%)$ were distribution, of the 138 messages coded, 17 (12.31\%) were explanation, and of the 138 messages coded, 85 (61.60\%) corresponded to action.

\section{DISSCUSSION}

The first conclusion that can be identified from this study is that the CDC prioritized internalization and action messages over distribution and explanation in the "Holiday Celebrations and Small Gatherings" section of the website. This seems to be an interesting finding because, in a research conducted in by Sellnow-Richmond et al. [10], the researchers found that, when communicating during the Ebola crisis of 2014 in the United States, the CDC sent tweets that would favor explanation and internalization over action. This finding demonstrates a clear shift in the communication strategy of the CDC. Such change could be partly due to the many sections of the CDC's website dedicated to explaining what COVID19 is, symptoms, how to prevent it, what to do if infected, among other relevant information. This conclusion also demonstrates the importance that the CDC has given to foster, in individuals, a sense of understanding about how they can be affected by COVID-19 during the holidays and how it can impact their loved ones. The CDC also dedicated a significant part of the website to incorporate messages that appealed to timeliness, proximity, and personal impact, strengthening the internalization component of the overall communication.

A recommendation that can be outlined from the above-mentioned conclusions is that to develop an even stronger sense of understanding about the messages, the CDC should include more messages that involve compassion and exemplars. Researchers consider that it is equally important to develop cognitive and affective outcomes in learning [8]. Sellnow-Richmond et al. [10] consider that Exemplars are vital because they "serve as effective cognitive shortcuts to increase understanding of complex information about the virus (explanation) and, ultimately, to foster appropriate selfprotective actions" (p. 142). Consequently, including compassion in messages is important because it leads to creating affective outcomes that are vital in achieving learning and self-efficacy during a crisis [8]. Regarding the Hispanic community, messages that seek affective outcomes should acknowledge the feelings of solitude and sadness that come from experiencing the holidays away from family members. It is important to remember that Hispanics come from collectivistic cultures that value group activities [4]. Hence, COVID-19 times can be difficult for them too.

An important conclusion related to the distribution element of the IDEA model is that in the "Holiday Celebrations and Small Gatherings" section of the website, the CDC did not direct individuals to access information through channels different than its website and other government websites. Sellnow and Sellnow [8] suggest that crisis and risk messages should be distributed through diverse channels to reach more audience members. Some of these channels can include but are not limited to radio, print media, text messages, and social media. This finding can turn into a recommendation for CDC and other health officials communicating about crisis and risk to diverse audiences. The more diversity on channels, the better. The CDC should enhance the text information distributed on its website by incorporating links to audiovisual components posted on its social media channels (Facebook, Twitter, Instagram, and YouTube).

A conclusion that can be drawn regarding the explanation and action components of the IDEA model is that the CDC effectively translated scientific information into simple terms when providing explanations and action steps. Researchers in this field consider that technical information should be translated for non-scientific audiences in order to achieve effectivity [8]. It is important to note that although the CDC incorporated all elements of the IDEA model in the messages, the information there was a mere translation of the English version of this section. In other words, the messages did not seem to be created to appeal to Hispanics intentionally. This finding seems particularly relevant for this study because the CDC [4] itself, in its "Cultural Insights" publication, even acknowledges the importance of adapting communications aimed at Hispanics to this community's cultural characteristics. In the same publication, the CDC even advises to "emphasize cultural diversity within the Hispanic population when conducting health assessments and promotion activities. Subgroups of the Hispanic population such as Mexicans, Puerto Ricans, and Cubans differ in their lifestyles, health beliefs, and health practices" (p.4). Thus, it can be said that at least in this "Holiday Celebrations and Small Gatherings" section, the CDC did not follow its own suggestions. Experts in crisis and risk communication agree that translating English messages to Spanish is not enough during emergencies and disasters [6]. Research has shown that tailoring crisis and risk messages to the different cultures and races within a population is useful to motivate protective actions, self-efficacy and reduce the knowledge gap [6]. Thus, a call for spokespersons, emergency managers, and other health officials is to separate from the habit of translating messages without incorporating relevant cultural aspects into their communications. Health organizations creating messages should engage opinion leaders from these vulnerable communities to develop and distribute these communications. Doing this can ensure that the crisis and risk communications match the communities' needs and cultural expectations. 
One limitation can be identified in this study, and it is that only one section from the CDC website was coded through the thematic analysis. Coding more areas of the website would have provided more details on the incorporation of the IDEA model elements throughout the CDC website. Future research should focus on analyzing other health officials' websites to understand the steps these organizations are taking to intentionally appeal to vulnerable populations, like Hispanics, during COVID-19 times.

\section{CONCLUSION}

The results of this study demonstrate that although the CDC is incorporating the components of the IDEA model (internalization, distribution, explanation, and action) into its communications, these are not incorporated equally. This situation can pose a problem when communicating to diverse audiences. Diverse levels of understanding about a crisis or risk and differences in learning styles can interfere with protective actions and self-efficacy. Especially now during COVID-19 times, when so many still struggle to adopt protective measures while cases are going up in the United States. This study also suggests a group of recommendations that health officials communicating to diverse audiences should consider when developing instructional crisis and risk messages.

\section{Author Biography}

Sofia Salazar is a student in the Strategic Communication PhD program at the Nicholson School of Communication and Media (UCF) and a Graduate Teaching Associate.

\section{REFERENCES}

[1] Bizjak, T., Yoon-Hendricks, A., Reese, P., \& Mcgough, M. (2020, June 09) Sacramento coronavirus cases are spiking and family home gatherings are a key cause. The Sacramento Bee. https://www.sacbee.com/news/coronavirus/article243376046.html

[2] Center for Disease Control and Prevention. (2020d, November 18). Health disparities: Race and Hispanic origin: https://www.cdc.gov/nchs/nvss/vsrr/covid19/health_disparities.htm

[3] Center for Disease Control and Prevention. (2020g, November 27). Celebraciones y pequeñas reuniones por las fiestas [Holiday Celebrations and Small Gatherings]. https://espanol.cdc.gov/coronavirus/2019-ncov/daily-lifecoping/holidays.html

[4] Center for Disease Control and Prevention. (n.d.). Cultural Insights. Communicating with Hispanics/Latinos. https://www.cdc.gov/healthcommunication/pdf/audience/audienceinsight_culturalinsights.pdf

[5] Krogstad, M., Stepler, R., \& Lopez, M. (2015, May 12). English Proficiency on the Rise Among Latinos. Pew Research Center. https://www.pewresearch.org/hispanic/2015/05/12/english-proficiency-on-the-rise-among-latinos/

[6] Petrun, E. L., Parker, A. M., Ramchand, R., Finucane, M. L., Parks, V., \& Seelam, R. (2019). Reaching vulnerable populations in the disaster-prone US Gulf Coast: Communicating across the crisis lifecycle. Journal of Emergency Management, 17(4), 271-286. https://doi.org/10.5055/jem.2019.0426

[7] Rodriguez, A. (2020, November 27). Fauci worries Thanksgiving may be the start of a dark holiday season if COVID-19 cases continue to soar. USA TODAY. https://www.usatoday.com/story/news/nation/2020/11/27/fauci-christmas-couldlook-lot-like-thanksgiving-amid-covid-surge/3777541001

[8] Sellnow, D. D., \& Sellnow, T. L. (2019). The IDEA model for effective instructional risk and crisis communication risk and crisis communication by emergency managers and other key spoke persons. Journal of Emergency Management, 17(1), 6778. https://10.05055/jem.2019.0899

[9] Sellnow, D. D., \& Sellnow, T. L. (n.d.) Effective communication in times of risk and crisis. Behavioral Sciences. www.researchoutreach.org

[10] Sellnow-Richmond, D. D., George, A. M., \& Sellnow D. D. (2018). An IDEA model analysis of instructional risk communication in the time of Ebola. Journal of International Crisis and Risk Communication Research, 1(1), 135-166. https://doi.org/10.30658/jicrcr.1.1.7 